\title{
Human-caused mortality influences spatial population dynamics: Pumas in landscapes with varying mortality risks
}

\author{
Jesse R. Newby a,b,*, L. Scott Mills ${ }^{a}$, Toni K. Ruth ${ }^{\mathrm{c}, 1}$, Daniel H. Pletscher ${ }^{\mathrm{a}}$, Michael S. Mitchell ${ }^{\mathrm{d}}$, \\ Howard B. Quigley ${ }^{\text {bee }}$, Kerry M. Murphy ${ }^{\text {f }}$, Rich DeSimone ${ }^{g}$ \\ ${ }^{a}$ Wildlife Biology Program, Department of Ecosystem and Conservation Sciences, University of Montana, Missoula, MT 59812, USA \\ ${ }^{\mathrm{b}}$ Craighead Beringia South, 6955 E 3rd St., Kelly, WY 83011, USA \\ ${ }^{\mathrm{c}}$ Hornocker Wildlife Institute/Wildife Conservation Society, $301 \mathrm{~N}$ Wilson Avenue, Bozeman, MT 59715, USA \\ ${ }^{\mathrm{d}}$ Wildlife Biology Program, U.S. Geological Survey, Montana Cooperative Wildlife Research Unit, University of Montana, Missoula, MT 59812, USA \\ e Panthera, 8 W 40th St., 18th Floor, New York, NY 10018, USA \\ f Bridger-Teton National Forest, 340 N Cache, Jackson, WY 83001, USA \\ ${ }^{\mathrm{g}}$ Montana Fish, Wildlife and Parks, Helena, MT 59620, USA
}

\section{A R T I C L E I N F O}

\section{Article history:}

Received 27 March 2012

Received in revised form 31 August 2012

Accepted 22 October 2012

\section{Keywords}

Dispersal

Population contribution

Puma concolor

Source-sink

Spatially structured populations

\begin{abstract}
A B S T R A C T
An understanding of how stressors affect dispersal attributes and the contribution of local populations to multi-population dynamics are of immediate value to basic and applied ecology. Puma (Puma concolor) populations are expected to be influenced by inter-population movements and susceptible to humaninduced source-sink dynamics. Using long-term datasets we quantified the contribution of two puma populations to operationally define them as sources or sinks. The puma population in the Northern Greater Yellowstone Ecosystem (NGYE) was largely insulated from human-induced mortality by Yellowstone National Park. Pumas in the western Montana Garnet Mountain system were exposed to greater human-induced mortality, which changed over the study due to the closure of a $915 \mathrm{~km}^{2}$ area to hunting. The NGYE's population growth depended on inter-population movements, as did its ability to act as a source to the larger region. The heavily hunted Garnet area was a sink with a declining population until the hunting closure, after which it became a source with positive intrinsic growth and a $16 \times$ increase in emigration. We also examined the spatial and temporal characteristics of individual dispersal attributes (emigration, dispersal distance, establishment success) of subadult pumas $(N=126)$. Human-caused mortality was found to negatively impact all three dispersal components. Our results demonstrate the influence of human-induced mortality on not only within population vital rates, but also inter-population vital rates, affecting the magnitude and mechanisms of local population's contribution to the larger metapopulation.
\end{abstract}

(c) 2012 Elsevier Ltd. All rights reserved.

\section{Introduction}

An understanding of how human-induced mortality affects dispersal characteristics and the role of local populations on the landscape is of immediate value to conservation (Braunisch et al., 2012). Recognizing that populations interact across heterogeneous environments (Revilla et al., 2004; Small et al., 1991; Thomas and Kunin, 1999), wildlife and fisheries managers are increasingly incorporating population spatial structure into conservation efforts (Botsford et al., 2009; McCullough, 1996; Rabinowitz and Zeller,

* Corresponding author. Address: Craighead Beringia South, Teton Cougar Project, 1495 Riverbend Road, Superior, MT 59872, USA. Tel.: +1 406822 0781; fax: +1 866 5218358.

E-mail address: jesse.newby@gmail.com (J.R. Newby).

1 Present address: Selway Institute, PO Box 92940, Heronwood Lane, Bellevue, ID 83313, USA
2010). Spatial management approaches are especially applicable when mortality operates differentially across the landscape (e.g. in and around protected areas) (Balme et al., 2010; Novaro et al., 2005; Woodroffe and Ginsberg, 1998) and for highly vagile and cryptic species (Joshi and Gadgil, 1991; McCullough, 1996).

Our understanding of stage-specific mortality effects on local population dynamics in vertebrates is well developed, with strong links between conceptual models and field data (Gaillard et al., 2000; Johnson et al., 2010; Oli and Dobson, 2003; Saether and Bakke, 2000). By contrast, few studies have explicitly linked field data to models of landscape population dynamics that account for influences of mortality on both within and among-population vital rates (Griffin and Mills, 2009; Runge et al., 2006).

Dispersal involves three distinct components: emigration from the natal range, movement between natal and breeding range, and successful establishment into that breeding range (Bowler 
and Benton, 2005; Howard, 1960). Due to the long and unpredictable movements inherent in dispersal events, estimating these components can be difficult (Cooper et al., 2008; Koenig et al., 1996; Morrison and Wood, 2009). If among and within-population vital rates can be derived from the field, however, the role of a local population within the multi-population context can be quantified and source and sink areas operationally identified (Griffin and Mills, 2009; Runge et al., 2006).

Pumas provide an example of the importance of inter-population processes and spatial structure for population ecology and management. Dispersal can have a prominent effect on puma population dynamics. For example, emigration can lead to local populations exhibiting lower growth rates than those expected from positive intrinsic vital rates (Cooley et al., 2009a; Robinson and DeSimone, 2011). Conversely, immigration can offset the population declines expected from negative intrinsic growth (Robinson et al., 2008). Pumas are also subject to mortality from hunting, depredation removals, and other conflicts with humans which can create source-sink dynamics (Cooley et al., 2009b; Robinson et al., 2008; Stoner et al., 2006; Thompson and Jenks, 2005).

We used long-term, large-scale demographic data from two puma populations with varying levels of human-induced mortality to determine how mortality affects spatial population dynamics. Specifically, we operationally defined the populations as sources and sinks based on within-population growth and between population exchange, and determined how these varied temporally. Additionally, we examined the effects of human-caused mortality on individual dispersal components (emigration, dispersal movement, and establishment success).

The Northern Greater Yellowstone Ecosystem (NGYE) puma population was largely insulated from anthropogenic risks. We used NGYE puma data from 2 periods. From 1987 to 1993 (hereafter "phase I") the puma population was increasing after control efforts within Yellowstone National Park (early 20th century) and persecution as a predator in surrounding areas (up to 1971) ceased (Murphy et al., 1999). During phase II (1998-2005) of NGYE research, the puma population was relatively stable and at a higher density (Ruth and Buotte, 2007).

In contrast to the NGYE, our second population in the Garnet Mountains of Montana was exposed to higher human-caused mortality. In the first 3 years of Garnet research (1997-2000), pumas were heavily hunted throughout the study area, but in subsequent years (2001-2006) hunting was restricted (Robinson and DeSimone, 2011). However, human-induced mortality remained relatively high over all years of Garnet research compared to the NGYE (Montana Fish, Wildlife and Parks hunt reports 19882007; (DeSimone and Semmens, 2005; Ruth et al., 2011). We hypothesized that after puma hunting was restricted in the Garnet area the population's per capita contribution to the region would increase in part due to higher levels of dispersal into surrounding subpopulations.

To help interpret changes in source-sink dynamics, we developed regression models of emigration, dispersal distance and establishment success to assess the influence of human-caused mortality. We tested the following predictions for how humancaused mortality could affect these three dispersal components:

(1) Emigration: Increases in the human-caused mortality rate would reduce the probability of subadults emigrating. The reduction of emigration could result from direct mortality on subadults or by opening up adult territories, thus encouraging philopatry (Cooley et al., 2009b).

(2) Dispersal distances: Dispersal distances would be shorter under higher levels of puma harvest. Harvest could influence dispersal distances directly by killing individuals as they dispersed and ending their movements. Heavy harvest could also create population turnover and open territories for settlement (Kluyver and Tinbergen, 1970; Waser, 1985) leading to settlement closer to natal areas.

(3) Establishment success: Dispersers in areas with heavy harvest would have a reduced probability of successfully surviving to establish an adult home range, due to direct mortality from harvest.

We assessed the influence of human-caused mortality on dispersal components by developing and testing competing models which also included effects of spatial/temporal variation, sex, and the presence of wolves.

\section{Study areas and methods}

\subsection{Study areas}

\subsubsection{Northern Greater Yellowstone Ecosystem (NGYE)}

The primary study area covered $3779 \mathrm{~km}^{2}$, including the northern range of Yellowstone National Park, the adjoining AbsorkaBeartooth Wilderness, and private and public lands in the Gardiner basin (Murphy, 1998; Ruth et al., 2011). Terrain is mountainous with steep broken canyons along the Yellowstone River and elevations ranging from 1500 to $2900 \mathrm{~m}$. Documentation of dispersal movements extended out $200 \mathrm{~km}$ from the study area across the Greater Yellowstone Ecosystem.

Wolves were reintroduced to Yellowstone's northern range in 1995 and increased over much of the phase II study (Smith et al., 2010). Pumas were displaced from their kills and occasionally killed by wolves (Ruth et al., 2008, 2011).

Pumas occupy the northern range of YNP year round but in winter the surrounding population is restricted to low elevation elk wintering range, making home ranges largely seasonal (Murphy, 1998). Minimum estimated annual density of independent adult and subadult pumas ranged from 3.0 to $10.7 / 1000 \mathrm{~km}^{2}$ over both study phases based on annual number observed via capture, telemetry, and snow tracking for the extent of area covered by all estimated adult home ranges combined (Murphy, 1998; Ruth and Buotte, 2007; Ruth et al., 2011).

Approximately $58 \%$ of the study area $\left(2224 \mathrm{~km}^{2}\right)$ was within park boundaries where hunting of pumas was not allowed, and $26 \%\left(974 \mathrm{~km}^{2}\right)$ was within Wilderness areas from which no pumas were harvested (Ruth et al., 2011). As pumas dispersed, they encountered primarily public lands, in Yellowstone and Grand Teton National Parks and National Forests and Wilderness (84.2\% public land).

\subsubsection{Garnet Mountains, Montana}

The study area was situated in $2500 \mathrm{~km}^{2}$ of the mountainous Blackfoot River Drainage, with elevations from 1160 to $2156 \mathrm{~m}$. Wolves also occurred rarely in the area, but no resident population was documented during the study period (Harris, 2007). Dispersal of individuals from the core Garnet study area extended the study area radius $80 \mathrm{~km}$ throughout the Blackfoot drainage. The Blackfoot drainage was comprised of $48 \%$ private lands with the remained made up of state and federal lands. Estimated minimum densities of independent pumas in the Garnet study area was $4.8-11.7 / 1000 \mathrm{~km}^{2}$, based on the number of observed individuals in the area covered by all adult home ranges combined (DeSimone and Semmens, 2005; Robinson and DeSimone, 2011).

In the Garnet study area, liberal hunting of pumas was permitted from 1997 to 2000 (pre-closure). Hunting was then prohibited in a $915-\mathrm{km}^{2}$ area until 2006 (closure), but continued throughout the surrounding Blackfoot Drainage (DeSimone and Semmens, 2005; Robinson and DeSimone, 2011). While individuals were 
more protected from hunting in the core study area, they could still be exposed to hunting outside of the closure.

Overall human-caused mortality was higher in the Garnet system than in NGYE. The proportion of the estimated independent puma population killed annually by humans in the Garnet study area (\%)rtality mean $=20.7 \%, 95 \% \mathrm{CI}=9.5-31.9$ ) was significantly higher than in the NGYE (\%mortality mean $=3.9 \%, 95 \% \mathrm{CI}=0.8-6.9$ ) (Robinson and DeSimone, 2011; Ruth et al., 2008, 2011). Similarly, harvest of pumas was greater in the hunt districts adjacent to the Garnet study area (annual puma harvest mean $=4.3 / 1000 \mathrm{~km}^{2}$; $95 \% \mathrm{CI}=1.5-7.2$ ) compared to areas adjacent to the NGYE study area (annual puma harvest mean $=0.6 / 1000 \mathrm{~km}^{2} ; 95 \% \mathrm{CI}=0.4-$ 0.8) (Robinson and DeSimone, 2011; Ruth et al., 2008, 2011).

\subsection{Field sampling}

Pumas $>3$ months of age were captured and immobilized using hounds. Kittens were captured in the den by hand at 5-8 weeks old or with hounds the following winter. All pumas were permanently marked and fitted with a VHF or GPS radio-collar with mortality switches (Murphy, 1998; Ruth et al., 2008, 2010). VHF collared individuals were relocated at 1-14 day intervals from the ground and the air. A subset of adult and subadult individuals were fitted with GPS collars beginning in 2001. All captures and handling protocols accorded with the University of Montana Institutional Animal Care and Use Committee standards (protocol \#04005SMWB-030106).

Minimum numbers of adult and subadult pumas were documented annually during winter through telemetry marking in combination with extensive snow track transects (1200$2850 \mathrm{~km} /$ winter) to detect unmarked individuals (DeSimone and Semmens, 2005; Murphy, 1998; Ruth and Buotte, 2007). Additional documentation of pumas in the study areas was gathered from resource management personnel, hound hunters, and state harvest records.

Detectability of independent pumas was assessed by back-calculating individuals captured as adults into the population based on their age, with the assumption females were philopatric and males entered the population at 2 years old. This allowed estimates of the proportion of independent pumas marked to the total number assumed to be in the population for all study years, excluding the last. This method may have underestimated detectablity as some individuals may have entered the population later than assumed. See Logan and Sweanor (2001; pp. 65-68), for additional details.

Using the back-calculating estimate, the study areas had similar detectability (NGYE mean $=73.4 \%$ SE $=8.56 \%$; Garnet mean $=82.1 \%$ $\mathrm{SE}=6.16 \%$ ). Despite the estimated accuracy of annual population estimates, we consider population estimates to be minimums because undocumented pumas may have used areas overlapping the study areas and transients may have passed through undetected.

\subsection{Emigration}

Dispersers are subadults, independent from their mothers but not yet established as breeding adults at approximately 24 months of age (Cooley et al., 2009b; Logan and Sweanor, 2001; Murphy, 1998). We censored from the dataset subadult pumas that died within their natal home ranges before 24 months old, and classified remaining subadults born in the study area as emigrants or philopatric. Emigrants were those that left their natal home range without returning. Philopatric individuals were those that survived to 24 months old and whose movements overlapped their natal range by $5 \%$ or more (95\% fixed kernel home range estimates; Logan and Sweanor, 2001).
The influence of covariates on the probability of subadult pumas emigrating was examined using generalized linear models with a binomial error structure. The influence of human-caused mortality was modeled using the proportion of the independent puma population killed by humans in the winter preceding individuals entering the subadult age class. Population density was included as a covariate using annual minimum estimates of the independent puma population for the year an individual became a subadult. The sex of the disperser was included because dispersal in pumas is typically male biased. Interaction terms between sex and human-caused mortality along with sex and density were included because harvest tends to be male biased and the sexes may respond differently to density (Cougar Management Guidelines Working Group, 2005; Ruth et al., 2011; Sweanor et al., 2000). Spatio-temporal effects were included in models as site specific change over time in emigration. Finally, the presence of a resident wolf population was included as a categorical variable (present vs. absent).

\subsection{Dispersal distance}

Post-emigration monitoring was conducted through aerial telemetry with approximately bi-monthly flights. Flights ranged up to a maximum of $200 \mathrm{~km}$ from the primary study area. Information for dispersal distance and fates were also supplied by hunter tag returns (41 of 125 dispersers), which sometimes provided documentation years after the disperser was lost to radio tracking.

Dispersal distance was measured as the Euclidean distance between a disperser's origin and final dispersal location. We fixed the origin of the dispersal event as the median location of the emigrant's natal range prior to dispersal. In the absence of adequate relocation data to determine a natal range ( $N=5$ of 86 pumas), the individual's pre-dispersal capture site was considered the origin. The final dispersal location was the median location of the individual's established adult home range post-dispersal, or in 44 out of 86 cases the individual's mortality site was used. In cases of lost contact, we used the last location obtained for the individual as a final dispersal location $(N=22)$. Estimates of dispersal distance should be considered minimums as individuals may have dispersed further than documented.

Differences in dispersal distance between study areas may reflect differences in the distribution of resources, conspecifics, competitors, and anthropogenic development all of which may act on disperser space use. To account for the area specific differences in space use we scaled dispersal distance by average home range diameter, which is also expected to vary with these factors (Labonte et al., 1998; Ruth and Buotte, 2007; Trewhella et al., 1988; Waser, 1985). Adult lifetime home ranges for each sex in both study areas were estimated using a 95\% fixed kernel and converted to represent an equivalently sized circular home range:

$2(\sqrt{(\text { home range area }) / \pi})$

Linear dispersal distances were then divided by this diameter to determine number of average home ranges traversed $\left(D_{h r d}\right)$.

We modeled covariate effects on $D_{\text {hrd }}$ using linear regression. The influence of human-caused mortality was assessed by including a categorical term indexing the level of harvest mortality in the area during the study (high $>1.4$ pumas $/ 1000 \mathrm{~km}^{2} /$ year; low $<1.4$ pumas/1000 $\mathrm{km}^{2} /$ year) (Robinson and DeSimone, 2011). This corresponded to our two study systems with the region surrounding the Garnet study area exhibiting high harvest mortality ( mean $=4.3$ pumas $/ 1000 \mathrm{~km}^{2} /$ year; $95 \% \mathrm{CI}=1.5-7.2$ ) and the region around the NGYE study area low (mean $=0.6$ pumas/ $1000 \mathrm{~km}^{2} /$ year; $95 \% \mathrm{CI}=0.4-0.8$ ). Harvest level was used as an index of human-caused mortality because detailed population and 
mortality data were unavailable outside the primary study areas. The amount of harvest was considered a suitable proxy because it is the primary source of human-caused mortality in both areas (Robinson and DeSimone, 2011; Ruth et al., 2011).

Models also included variables for study area specific change over time, sex, wolf presence, and individual's fate. The fate of the disperser, whether it was killed, survived, or was lost during dispersal, was included because early mortality or loss of contact could reduce distance estimates.

\subsection{Disperser success}

Each disperser was classified as successfully establishing a home range, mortality while transient, or as contact lost. Because female pumas typically establish an adult home range by 24 months old, we assumed successful dispersal of radio-collared females when movement localized and remained stable until they were $>24$ months old (Cooley et al., 2009b; Logan and Sweanor, 2001; Murphy, 1998).

The completion of male dispersal was complicated by a tendency to restrict movements during their first winter after leaving their natal range, and then abandoning these temporary home ranges to continue dispersal (Beier, 1995). Therefore, males were not assumed to have ended their transient movements until the beginning of autumn (September 23rd) following their first winter independent from their mothers. Cats that could not be reliably relocated using radio-telemetry but were later relocated from tag returns (19 of 86 dispersers) were considered successful dispersals if they reached adulthood. Dispersers that died before reaching adulthood were considered to have failed to successfully establish.

Dispersal success was modeled using generalized linear regression models with a binomial error structure. Variables examined included harvest level, study area specific change over time, sex, and the presence of wolves as described above.

\subsection{Model fitting and selection}

Models examining the influence of covariates on dispersal components were evaluated in an AIC framework. Prior to multivariate model fitting, variables were tested to ensure independence $(\leqslant 0.6$ correlation). Univariate models were fit to assess assumptions of normality and linearity through inspection of residual plots, and transformations were explored to assess their ability to improve model fit.

Akaike's information criterion corrected for small sample sizes $\left(\mathrm{AIC}_{\mathrm{C}}\right)$ was used in model selection. Models within $2 \Delta \mathrm{AIC}$ units were considered strongly supported. Explanatory variables identified in these models were ranked in importance based on the sum of AIC weights $\left(w_{j}\right)$ and estimates of parameters and variance were made using full multimodal inference (MMI) (Burnham and Anderson, 1998).

All data summations and statistical analyses were performed using R, version 2.9.1 (The R Foundation for Statistical Computing, 2009).

\subsection{Population contribution}

We estimated annual per capita contribution of each population to metapopulation growth $\left(C^{r}\right)$, accounting for both recruitment of philopatric individuals into the population $\left(R^{r}\right)$, as well as recruits provided to other subpopulations via successful emigration $\left(E^{r}\right)$ (Runge et al., 2006). The annual self-recruitment rate $(R)$ of the local population $(r)$, was estimated by the annual observed growth (minus immigration) in the independent age class (subadults and adults). Thus,

$R^{r}=\lambda^{r}-I^{r}$ where $\lambda^{r}$ is the annual observed proportionate change in population size of independent pumas from December to December. The term $I^{r}$ denotes the annual per capita rate of immigration into the population. Although abundance and immigration rates were derived from the annual near-complete census surveys described above, the expected minor sampling variance could not be separated from process variance.

We estimated the contribution made by the local population via successful dispersal to other subpopulations, $\left(E^{r}\right)$ with:

$E^{r}=\varepsilon_{j}^{r} * \sum \Phi_{j}^{r s}$

where $\varepsilon_{j}^{r}$ is the proportion of independent pumas emigrating from the study area $(r)$ annually, $\Phi_{j}^{r s}$ is the average successful immigration of a disperser from $(r)$ into other subpopulations $(s)$ and the subscript $j$ denotes that individuals are independent subadults (the dispersal age class). Emigration was obtained through radiotelemetry and tag return data on the number of individuals emigrating from their natal range (and from the study area) divided by the number of independent pumas estimated in the population that year. Successful immigration into another subpopulation was estimated based on the proportion of all emigrants with known fates that survived to establish an adult home range outside the study area. The average success of individuals of known fates across the study period was used in each annual calculation.

The average annual per capita contribution $C^{r}$ of a population was thus estimated over " $t$ " years of study:

$C^{r}=\left(\left(\lambda^{r}-I^{r}\right)+\left(\varepsilon_{j}^{r} * \sum \Phi_{j}^{r s}\right)\right) / t=\left(R^{r}+E^{r}\right) / t$

Annual $C^{r}>1$ indicates that the local population was a net contributor to the metapopulation and acting as a source, while a $C^{r}<1$ indicates the population acted as a sink (Runge et al., 2006). Note that a local population that is not maintaining itself by self-recruitment $\left(R^{r}<1\right)$ can still act as a source via dispersal to other subpopulations.

The contribution of the NGYE was estimated separately for phase I (1987-1992), while the population was expanding, and in phase II (1999-2003) after wolves were reintroduced and the puma population plateaued (Ruth and Buotte, 2007). The contribution of the Garnet study area was also examined over two time periods, when hunting was permitted in the core of the study area (pre-closure: 1997-2000) and after hunting was restricted to areas outside of the core study area (closure: 2000-2006).

\section{Results}

\subsection{Field sampling}

Dependent kittens marked during research totaled 200 (NGYE $n=116$; Garnet $n=84$ ) and 113 of these kittens were monitored to subadult age (NGYE $n=61$; Garnet $n=52$ ). Additional pumas born on the study areas initially captured as subadults increased the total number of marked subadults to 126 (NGYE $n=68$; Garnet $n=58)$. Of these marked individuals, 104 (83\%) were monitored until their fate (death or successful establishment as adults) could be determined (NGYE $n=53$; Garnet $n=51$ ).

\subsection{Emigration}

NGYE showed no sex differences in the proportion of males and females emigrating (27/33 for males; $26 / 35$ for females), but in the Garnet system a greater proportion of males (19/26) than females (14/32) emigrated. Whereas a higher proportion of males than females emigrated in the Garnet study overall, in years when hunting occurred in the core study area no males dispersed (0/4) and $25 \%$ of females dispersed (1/4). Thus, during years hunting was 
Table 1

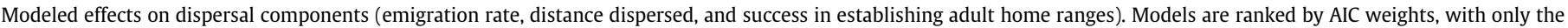
best supported models $(<2 \Delta \mathrm{AIC})$ shown.

\begin{tabular}{|c|c|c|c|c|c|c|}
\hline Rank & Emigration model & $n$ & df & $\mathrm{AIC}_{c}$ & $\triangle \mathrm{AIC}$ & Weight $\left(w_{i}\right)$ \\
\hline 1 & Density + HC Mort ${ }^{\mathrm{a}}+\mathrm{Sex}$ & 119 & 115 & 124.28 & 0 & 0.143 \\
\hline 2 & Density + HC Mort + Sex + HC Mort:Sex + Study Area & 119 & 113 & 124.35 & 0.069 & 0.138 \\
\hline 3 & Density + HC Mort + Sex + Study Area & 119 & 114 & 124.84 & 0.56 & 0.108 \\
\hline 4 & Density + HC Mort + Sex + Density:Sex + HC Mort:Sex & 119 & 113 & 125.27 & 0.989 & 0.087 \\
\hline 5 & Density + HC Mort + Sex + Density:Sex + HC Mort:Sex + Study Area & 119 & 112 & 125.56 & 1.278 & 0.075 \\
\hline 6 & Density + HC Mort + Sex + HC Mort:Sex & 119 & 113 & 125.58 & 1.299 & 0.075 \\
\hline \multirow[t]{2}{*}{7} & Density + HC Mort + Sex + Wolves ${ }^{\mathrm{b}}$ & 119 & 114 & 125.76 & 1.48 & 0.068 \\
\hline & Dispersal distance ${ }^{\mathrm{c}}$ model & & & & & \\
\hline 1 & Hunt Level ${ }^{\mathrm{d}}+$ Sex + Wolves & $\overline{81}$ & 76 & 48.92 & 0 & 0.223 \\
\hline 2 & Hunt Level + Fate + Sex + Harvest Level:Sex + Wolves & 81 & 74 & 49.77 & 0.851 & 0.146 \\
\hline \multirow[t]{2}{*}{3} & Hunt Level + Sex + Harvest Level:Sex & 81 & 77 & 50.48 & 1.564 & 0.102 \\
\hline & Disperser success model & & & & & \\
\hline 1 & Hunt Level + Sex & 64 & 61 & 79.32 & 0 & 0.193 \\
\hline 2 & Hunt Level + Sex + Wolves & 64 & 60 & 80.14 & 0.83 & 0.128 \\
\hline 3 & Sex + Wolves & 64 & 61 & 80.25 & 0.935 & 0.121 \\
\hline 4 & Sex + Study Area:Time & 64 & 60 & 80.57 & 1.258 & 0.103 \\
\hline 5 & Hunt Level + Sex + Study Area:Time & 64 & 58 & 80.81 & 1.499 & 0.091 \\
\hline 6 & Hunt Level + Sex + Harvest Level:Sex & 64 & 60 & 80.97 & 1.658 & 0.084 \\
\hline
\end{tabular}

${ }^{\text {a }}$ HC Mort = Annual proportion of population killed from human-causes.

b Wolves = Catagorical variable indicating presence of a resident wolf population.

c Dispersal distance measured as number of average home range diameters crossed $\left(D_{\text {hrd }}\right)$.

${ }^{\mathrm{d}}$ Hunt Level $=$ Level of puma harvest in an area categorized as (high $>1.4$ pumas $/ 1000 \mathrm{~km}^{2} /$ year).

permitted throughout the core Garnet area only one emigration was documented in 3 years. After hunting was restricted annual emigration increased to 2-8 emigrants per year.

The best supported model of puma emigration included terms for puma density, human-caused mortality, and subadult's sex (AIC weight $=0.143$ ). Six other models were within $2 \Delta$ AIC units of the top model and were considered strongly supported (Table 1). These models also included effects of study area, wolf presence, and interaction terms between sex and human-caused mortality and density. Based on multi-model inference (MMI) across all models, variables ranked in importance as: density $\left(w_{j}=1.0\right)$, human-caused mortality $\left(w_{j}=0.995\right)$, sex $\left(w_{j}=0.988\right)$, study area $\left(w_{j}=0.541\right)$, human-caused mortality:sex $\left(w_{j}=0.479\right)$, density:sex (0.33), wolves $\left(w_{j}=0.313\right)$ (Appendix A).

Parameter estimates from MMI showed emigration was negatively associated with both density $(\beta=-0.147, \mathrm{SE}=0.106)$ and human-caused mortality $(\beta=-3.902, \mathrm{SE}=1.755)$. Emigration was greater for males $(\beta=1.83, \mathrm{SE}=0.9)$ and for individuals in the NGYE ( $\beta=0.323, \mathrm{SE}=0.238$ ). Male were especially influenced by human-caused mortality and density (male:human-caused mortality: $\beta=-2.829, \quad \mathrm{SE}=1.795 ; \quad$ male: density: $\beta=-0.056$, $\mathrm{SE}=0.057)$. Some models indicated greater emigration tendencies in the presence of a resident wolf population $(\beta=0.075, \mathrm{SE}=0.09$ ).

\subsection{Dispersal distance}

Absolute dispersal distances for males and females in the NGYE were similar, with mean Euclidean dispersal distance of $67.4 \mathrm{~km}$ $(\mathrm{SE}=3.9, N=24)$ for females and $62 \mathrm{~km}(\mathrm{SE}=7.1, N=25)$ for males. However, NGYE females dispersed more of their respective home range diameters than males (females $3.08 D_{\text {hrd }}, \mathrm{SE}=0.43$; males $1.81 D_{\text {hrd }}, \mathrm{SE}=0.21$ ) (Fig. 1). Garnet area males dispersed further than females in absolute distance (males $42.6 \mathrm{~km}, \mathrm{SE}=2.6$, $N=18$; females $24.2 \mathrm{~km}, \mathrm{SE}=2.6, N=14$ ). However, after scaling for home range size there was little difference (male $D_{\text {hrd }}=1.44$, $\mathrm{SE}=0.13$; female $D_{h r d}=1.3, \mathrm{SE}=0.14$ ). In terms of $D_{h r d}$, females in the NGYE dispersed further than any other group (all two-tailed $t$-test between NGYE females and other groups, $p<0.013$ ).

The top model of dispersal distances scaled by home range size $\left(D_{h r d}\right)$ included effects for disperser sex, harvest level, and the presence of wolves (AIC weight $=0.223$ ). Two models were within $2 \triangle$ AIC units of the top model and included the additional factor of disperser fate and an interaction between sex and harvest level (Table 1). Variables were ranked by importance as sex $\left(w_{j}=0.931\right)$, harvest level $\left(w_{j}=0.871\right)$, sex: harvest level $\left(w_{j}=0.7\right)$, wolves $\left(w_{j}=0.597\right)$, and disperser's fate $\left(w_{j}=0.417\right)$ (Appendix A).

Parameter estimates indicated a negative association between males and $D_{\text {hrd }}(\beta=-0.576, \mathrm{SE}=0.181)$ as well harvest level and $D_{\text {hrd }}(\beta=-0.682, \mathrm{SE}=0.227)$. An interaction between sex and harvest level indicated dispersal distance for males was higher than expected given high harvest levels $(\beta=0.67, \mathrm{SE}=0.283)$. There was evidence that dispersal distances were greater in the presence of a resident wolf population $(\beta=0.262, \mathrm{SE}=0.139$ ). Individuals that died before completing dispersal had shorter dispersal distances $(\beta=-0.637, \mathrm{SE}=0.028)$, as did individuals for which contact was lost $(\beta=-0.554, \mathrm{SE}=0.03)$.

\subsection{Disperser success}

Females were more successful in surviving dispersal to establish an adult home range than males (Fig. 2). In addition, individuals dispersing in the NGYE were more likely to successfully disperse than their same sex counterparts in the higher mortality Garnet area. This pattern was also observed in the median ages at death for all individuals with known fates, inclusive of those that established. Median age at death for females after they dispersed was 55.8 and 30.8 months in the NGYE and Garnet areas, respectively. For male dispersers, the median age at death was 30.5 and 21.6 months in the NGYE and Garnets, respectively.

In the Garnet system all known mortalities of dispersing males (17 mortalities) and females (6 mortalities) were human-caused. Of the 21 documented mortalities of males dispersing from the NGYE study area, 16 were killed by hunters. Of 13 NGYE female mortalities 8 were human-caused. The remaining NGYE disperser mortalities were from natural causes such as fights with conspecifics and infections.

The top model examining the success of dispersers in surviving to establish home ranges included terms for disperser's sex and harvest level (AIC weight $=0.193$ ). Five competing models were within $2 \triangle$ AIC units and included effects for wolves, study area 


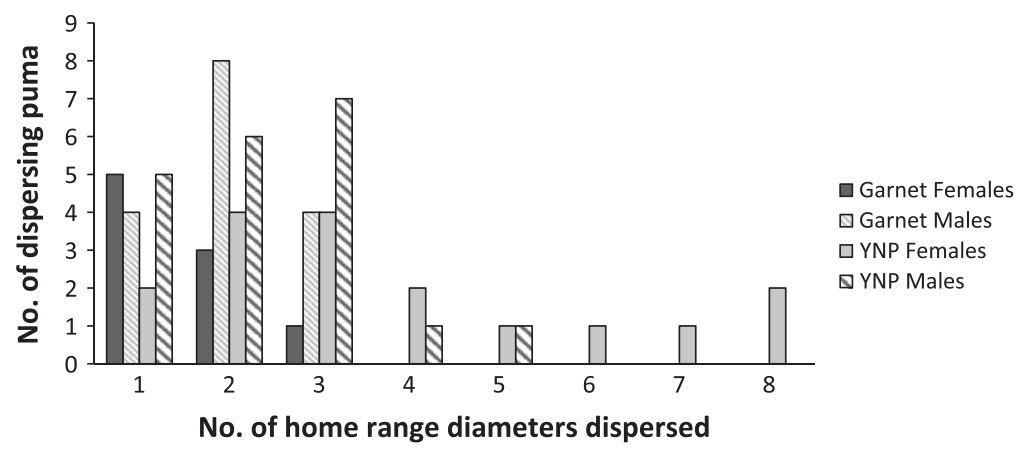

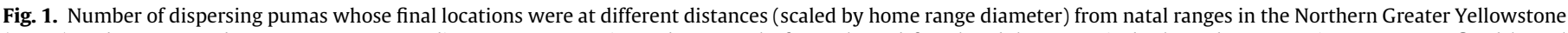

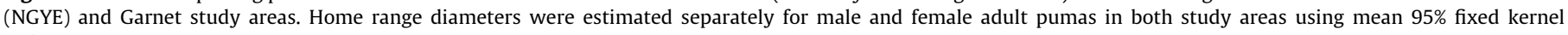
estimates.

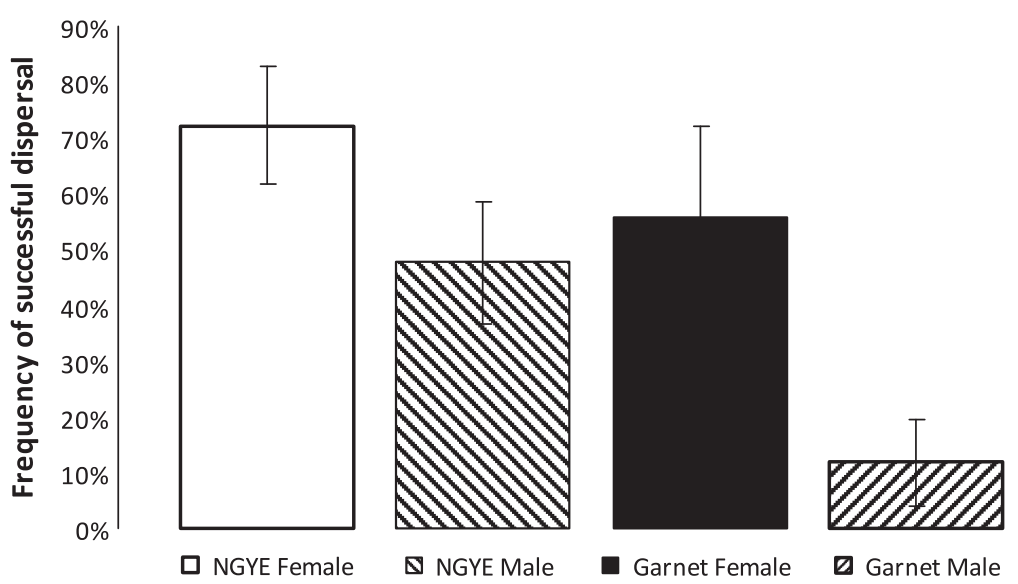

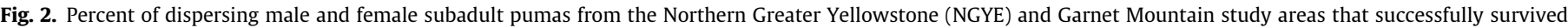

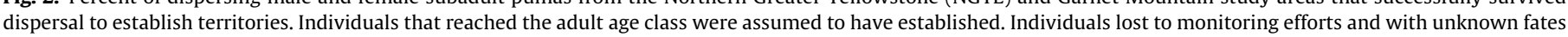
have been omitted. Error bars represent standard error.

specific changes over time, and an interaction between sex and harvest level (Table 1 and Appendix A). Variables were ranked by importance as sex $\left(w_{j}=0.969\right)$, harvest level $\left(w_{j}=0.703\right)$, wolves $\left(w_{j}=0.505\right)$, time:study $\left(w_{j}=0.384\right)$, and sex:harvest level (0.217). Males were less likely to survive dispersal as were individuals in the high harvest level area $\left(\operatorname{Sex}_{\text {(male) }} \beta=-1.18, \mathrm{SE}=0.378\right.$; Harvest Level $_{(\text {high) }} \beta=-139.3, \mathrm{SE}=85.77$ ). Models indicated a positive association between disperser success and areas with a resident wolf population $(\beta=0.817, \mathrm{SE}=0.472)$. An increase in disperser success over time was suggested for the Garnet study $(\beta=0.036, \mathrm{SE}=0.34)$, as was a decrease in success in the NGYE over time $(\beta=-0.034, \mathrm{SE}=0.033)$. Dispersers sex appeared to interact with harvest such that male success was especially impacted under high harvest $(\beta=-0.375, \mathrm{SE}=0.105)$.

\subsection{Population contribution}

The estimated mean annual growth rate of the NGYE independent puma population during Phase I (from 1987 to 1992) was $\lambda=1.11(95 \%$ CI 1.03-1.18), subsidized by a high average per capita

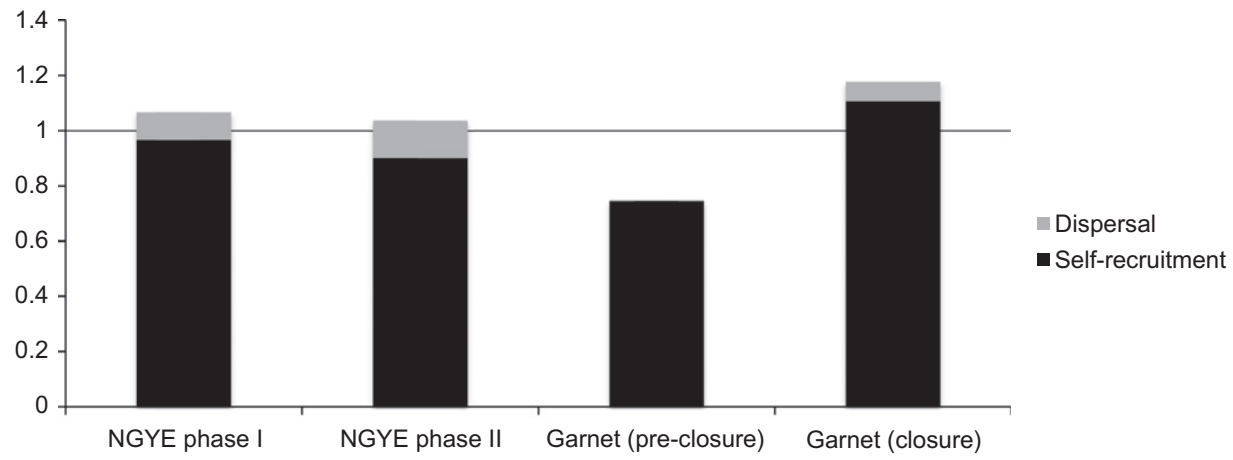

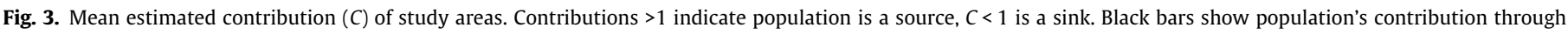

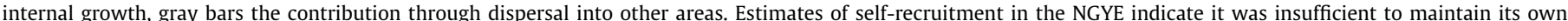

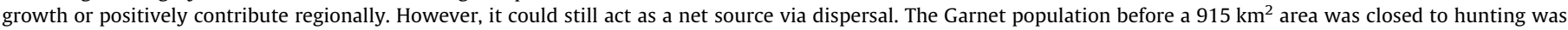
declining with little dispersal. After the closure it contributed both through its own growth and dispersal. 
annual immigration rate of $0.14(\mathrm{SE}=0.03)$. Removing the population growth attributable to immigration provided a mean annual self-recruitment rate of $R=0.98,(95 \% \mathrm{CI}=0.92-1.03)$. After accounting for subadults emigrating from the NGYE $(\varepsilon=0.17$, $\mathrm{SE}=0.07)$ and the probability of surviving to establish in a new area $\left(\sum \Phi_{j}^{r s}=0.59, \mathrm{SE}=0.08\right)$, the net annual contribution rate of the NGYE averaged $C=1.1$ (95\% CI 0.96-1.23). Assuming a normal distribution, $98 \%$ of estimates give $C>1$ in phase I of NGYE research. In Phase II of NGYE research (1999-2003) puma population growth appeared to be stationary to slightly negative, $\lambda=0.95$ (95\% CI 0.84-1.06), with low per capita immigration rate of 0.05 $(\mathrm{SE}=0.02)$. Per capita emigration rate remained high $(\varepsilon=0.23$, $\mathrm{SE}=0.05)$ and after accounting for disperser success $\left(\sum \Phi_{j}^{r s}=0.59, \mathrm{SE}=0.08\right)$ the population remained a source [( $C=1.05$; 95\% CI $0.95-1.15) ;(C>1$ in $95 \%$ of estimates $)]$ (Fig. 3$)$.

During pre-closure years of Garnet research (1997-2000), estimates indicated a declining puma population $(\lambda=0.75 ; 95 \% \mathrm{CI}$ $0.46-1.04)$. Little emigration from the study area occurred during this period $(\varepsilon=0.01, \mathrm{SE}=0.01)$ and disperser survival was low $\left(\sum \Phi_{j}^{r s}=0.27, \mathrm{SE}=0.09\right)$, resulting in a population sink with $C=0.76$ (95\% CI 0.47-1.0). However, when hunting was restricted (between 2000 and 2006) the population grew $(\lambda=1.12 ; 95 \% \mathrm{CI}$ $0.91-1.34)$, per capita emigration rate increased $(\varepsilon=0.27$, $\mathrm{SE}=0.09)$, and after accounting for disperser survival $\left(\left(\sum \Phi_{j}^{r s}=0.27, \mathrm{SE}=0.09\right)\right.$, the population became a source ( $C=1.21$; 95\% CI 1.02-1.39) (Fig. 3).

We did not confirm any immigration into the Garnet population during the years the population was studied. Any undetected immigrants would positively bias estimates of contribution as increases would be attributed to within population recruitment. However, undetected immigrants were unlikely to have qualitatively changed Garnet's post-closure source designation, because to cause $C<1$ would require an unlikely high undetected immigration rate $(I>0.18)$.

\section{Discussion}

We brought together extensive field datasets from 2 study areas to quantify puma dispersal characteristics and explore the landscape-level effects of human-induced mortality on these characteristics. Furthermore, we used inter-population vital rate estimates, coupled with estimated within-population growth, to quantify each population's contribution to landscape-level dynamics and operationally define them as sources or sinks (Griffin and Mills, 2009).

\subsection{Population contribution}

In both study areas we found that inter-population movements largely modulated both local population growth and the population's contribution to the surrounding region. For example, the observed self-recruitment rate in the NGYE was not sufficient to maintain positive population growth and was supported by immigration. Despite this, the population was a net source because it consistently exported large numbers of recruits to other subpopulations. This illustrates how a failure to account for dispersal can lead to faulty conclusions about the role a population plays in its regional context (Figueira and Crowder, 2006; Griffin and Mills, 2009; Gundersen et al., 2001). In the case of the NGYE, ignoring the contribution via dispersal would suggest the population was a sink, whereas not accounting for immigration would fail to show its own dependence on immigration. Indeed, the NGYE may be a "dependent source" which acts as a source of recruits for surrounding areas, but relies on immigration for its own growth (Franklin et al., 2004; Hixon et al., 2002). Therefore, to retain natural population processes it may be advisable to conserve multiple, mutually supportive source areas, especially when annual contribution is variable as in our study populations.

The potential effects of elevated human-induced mortality on within-population effects are well established. We found humaninduced mortality can also affect interpopulation vital rates with consequences for local and regional populations. Under heavy hunting pressure, the Garnet puma population was acting as a sink with a declining population and little emigration. After the creation of a small refuge $\left(915 \mathrm{~km}^{2}\right)$, and reduced hunting in the surrounding area, it quickly became a source. The increased contribution was due to both internal growth and an increase in per capita emigration leading to a 16-fold increase in absolute number of emigrants/year. Our findings support Robinson and DeSimone (2011) conclusion that even a relatively small area $\left(1000 \mathrm{~km}^{2}\right)$ with adequate habitat quality may act as a source for large felids, provided mortality is minimized.

\subsection{Emigration, dispersal distance and establishment success}

Interpopulation dynamics, and their population consequences, will depend on the characteristics of dispersal including emigration, dispersal distance, and establishment success (Bowler and Benton, 2005; Howard, 1960). Human-caused mortality was found to reduce all three of these dispersal components.

\subsubsection{Emigration}

After accounting for other explanatory variables, we found annual emigration rates were reduced by the amount of humancaused mortality in the population. Despite the strong emigration tendencies exhibited by males, human-caused mortality was found to especially impact male emigration. This is likely the result of males being more heavily targeted by trophy hunting, the primary source of human-caused mortality. Human-caused mortality directly altered male emigration by killing males before they could emigrate from their natal area. For example, when heavy hunting was allowed throughout the Garnet study area all males were killed immediately after becoming independent from their mothers.

Female emigration appeared to be influenced more indirectly by human-caused mortality. Whereas females in the more secure NGYE emigrated at high rates, females in the higher mortality Garnets had much lower emigration rates. Higher population turnover in the Garnet area appeared to provide available territories near the natal area, which reduced female emigration rates by encouraging philopatry (Matthysen, 2005; Sutherland et al., 2002; Wolff, 1997).

In addition to the negative effects of human-caused mortality, some models suggested emigration may increase in the presence of a resident wolf population. Emigration in the NGYE study area did show an increase after wolves were reintroduced to the area. The presence of wolves may have encouraged subadult pumas to emigrate from the area directly or through this change in the spatial distribution of conspecifics. Ruth and Buotte (2007) found NGYE pumas altered space use towards more steep, rugged terrain such as canyon areas after wolf reintroduction. These changes in space use may have influenced emigration. However, we caution that the generalities of our finding are limited because we only examined one system where wolves had become reestablished. In addition, the association between puma emigration and wolves was not strongly supported after accounting for other explanatory variables.

\subsubsection{Dispersal distance}

The second dispersal component, dispersal distance, was also influenced by human-induced mortality. After accounting for sex and site specific differences in space use, we found dispersal distances were reduced under heavy harvest. 
Sex differences found in models were unexpected. While dispersal distances in pumas are usually considered male biased, we found females dispersed relatively further in terms of their home range size. In addition heavy harvest impacted female dispersal distances to a greater extent than males. This was unexpected because males are more subject to direct mortality from trophy hunting. It is possible even the lower levels of harvest were adequate to significantly impact males, making differences in low vs. high harvest less pronounced than they were for females.

The pronounced effects of harvest on female dispersal distance likely arose from indirect effects. Disperser mortalities that ended dispersal negatively impacted dispersal distance. However, after accounting for this mortality, the effects of heavy harvest remained influential, indicating direct mortality did not mediate the effects of harvest. High population turnover from human-caused mortality likely indirectly reduced dispersal distances by opening territories, encouraging settlement near dispersers' natal range (Gundersen et al., 2002; Smith, 1993; Stoner et al., 2006; Wielgus et al., 2001).

Our results suggest that when population exchange is desirable between areas the intervening matrix distances should be short and/or have low human-caused mortality. In our study system, limiting the distance between populations separated by a moderately high mortality matrix to $<3$ average female home range diameters may be advisable for population interchange.

Aside from the influence of the conspecific population, dispersal distances may be further modified by interspecific competitors (Williamson, 2004). The effect of a resident wolf population was identified in top models as increasing puma dispersal distances. Interference competition with wolves can be lethal and it is plausible that the presence of wolves would discourage settlement and lead to further prospecting by dispersing pumas (Ruth, 2004; Ruth and Murphy, 2010). In addition, wolves could influence dispersal distance by changing the spatial distribution of the resident puma population or prey resources. As with emigration, the inferences of our findings concerning puma dispersal distance and wolves is limited to the NGYE area.

One factor unaccounted for in our examination of humancaused mortality effects on dispersal distance was other forms of anthropogenic disturbance, especially roads. In our study, high harvest levels corresponded to areas of higher road density. These factors are likely not independent. Road density has been correlated with increased human-caused mortality in carnivores, including pumas (Ruth et al., 2011; Schwartz et al., 2010). Previous research suggests roads may constrain or facilitate puma movements under various conditions (Beier, 1995, 2010; Newby, 2011). Secondary dirt roads, the majority of roads in our study areas, are found to have little negative affect and may even facilitate movements (Beier, 2010). This suggests road effects are unlikely to qualitatively alter the conclusion that higher harvest levels reduced dispersal distances.

\subsubsection{Establishment success}

Finally, we found that successful establishment of dispersers was also influenced by human-induced mortality. After accounting for other variables, models suggested both sexes were less likely to survive dispersal under heavy hunting. However, males were especially impacted by human-caused mortality. All well supported models showed males having overall lower survival than females. In addition, some models suggest male success was even lower than expected at high harvest levels. This result is not surprising because males are more susceptible to trophy hunting.

The impact of human-caused mortality is further illustrated by the poor (12\%) survival of males dispersing in the Garnet system, compared to the more secure NGYE where $48 \%$ of males survived. Following the same trend, $56 \%$ of Garnet females survived to estab- lish home ranges compared to $72 \%$ of NGYE females. All documented mortalities in the Garnet system were human-caused. Furthermore, median ages of death for male emigrants from both study areas along with Garnet females were less than 31 months. This indicates the low potential for genetic contribution of males in both studies and females under high human-caused mortality (Logan and Sweanor, 2001; Murphy, 1998; Ross and Jalkotzy, 1992).

\subsection{Conclusion}

We found that puma populations subject to high human-induced mortality showed reduced dispersal, with effects evident on each component of dispersal (emigration, dispersal distance, and establishment). We found male pumas were more directly affected by elevated pre- and post-emigration mortality. The effects of high population turnover on females were largely indirect. Among female pumas we observed reduced emigration rates, greater philopatry, shorter dispersal distances and an overall reduction in the extent of interpopulation exchange under elevated human-induced mortality. This was likely the result of high turnover in the resident puma population providing territory openings for subadult females.

Interestingly, although the rate and extent of dispersal is generally considered male biased in pumas, we found female dispersal in the relatively secure NGYE was comparable to males (Laing and Lindzey, 1993; Ross and Jalkotzy, 1992; Sweanor et al., 2000). Given the lower survival rates for male dispersers in our study areas, this suggest females could contribute more to interpopulation exchange than males in some populations.

We conclude human-caused mortality can have important consequences for both within- and between-population dynamics, even influencing source-sink dynamics. For management applications based on spatially structured approaches that rely on source populations, we suggest explicit consideration of mortality effects on interpopulation movements.

\section{Acknowledgements}

Research was supported by Craighead Beringia South, Hornocker Wildlife Research Institute, Montana Department of Fish Wildlife \& Parks, Montana Cooperative Wildlife Research Unit, Panthera, Panthera-Kaplan Graduate Awards Program, Richard King Mellon Foundation, Summerlee Foundation, University of Montana, U.S. Geological Survey, Wildlife Conservation Society, and Yellowstone National Park. LSM acknowledges support from NSF DEB (0841884) and USGS National Climate Change and Wildlife Science Center. Our thanks to L. Anderson, S. Ard, B. Chapman, D. Chapman, R. Gipe, S. Monger, D. Powell, D. Stradley, and R. Stradley for flying services. Successful data collection was made possible by the efforts of D. Beaver, P. Buotte, S. Carsen, T. Chilton, J. Cole, T. Coleman, R. Cooper, W. Craddock, V. Edwards, G. Felzien, T. Fredrickson, M. Graf, G. Hedrick, T. Hollow, B. Holmes, J. Husseman, R. Jaffe, A. Jakes, M. Johnson, C. Kelly, T. Knuchel, M. Maples, S. McGee, D. Powell, J. Powers, S. Powers, S. Relyea, M. Sawaya, B. Semmens, E. Shanahan, B. Sheppard, B. Shinn, S. Shrout, B. Shultz, J. Sikich, D. Stahler, M. Trapkus, B. Wiesner. M. Hornocker and L. Hunter provided steadfast support. Special thanks to $\mathrm{H}$. Robinson and P. Buotte for their insightful advice concerning analytical approaches and puma ecology. Thanks to D. Smith and D. Thompson for reviewing the manuscript. The use of trade names or products does not constitute endorsement by the U.S. Government.

\section{Appendix A}

See Table A1. 


\section{Table A1}

Variables included in all top models ( $\triangle$ AIC $<2$ ) of dispersal components (emigration, dispersal distance, and successful establishment). Variables are ranked based on AIC weights and parameter estimates with standard errors are provided based on full multi-model estimates. Only variables and their interactions included in top models are shown.

\begin{tabular}{|c|c|c|c|c|}
\hline Variable & Rank & $w+(j)$ & Est $\beta_{(j)}$ & $\mathrm{SE}_{(j)}$ \\
\hline \multicolumn{5}{|l|}{ 1. Emigration } \\
\hline Density & 1 & 1 & -0.143 & 0.106 \\
\hline HC Mort ${ }^{\mathrm{a}}$ & 2 & 0.995 & -3.902 & 1.755 \\
\hline $\operatorname{Sex}_{(\text {male })}$ & 3 & 0.988 & 1.83 & 0.899 \\
\hline Study Area (NGYE) & 4 & 0.541 & 0.323 & 0.238 \\
\hline $\operatorname{Sex}_{(\text {male })}:$ HC Mort & 5 & 0.479 & -2.829 & 1.795 \\
\hline $\operatorname{Sex}_{(\text {male) }}$ :Density & 6 & 0.33 & -0.056 & 0.057 \\
\hline Wolves $^{\mathrm{b}}$ & 7 & 0.313 & 0.075 & 0.09 \\
\hline \multicolumn{5}{|l|}{ 2. Dispersal distance ${ }^{c}$} \\
\hline $\operatorname{Sex}_{(\text {male })}$ & 1 & 0.931 & -0.576 & 0.181 \\
\hline 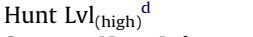 & 2 & 0.871 & -0.682 & 0.227 \\
\hline $\operatorname{Sex}_{(\text {male })}:$ Hunt Lvl (high) & 3 & 0.698 & 0.67 & 0.283 \\
\hline Wolves & 4 & 0.597 & 0.262 & 0.139 \\
\hline Fate $_{\text {(died) }}$ & 5 & 0.417 & -0.637 & 0.028 \\
\hline Fate $_{(\text {lost })}$ & 6 & 0.417 & -0.554 & 0.03 \\
\hline \multicolumn{5}{|l|}{ 3. Dispersal success } \\
\hline $\operatorname{Sex}_{(\text {male })}$ & 1 & 0.969 & -1.18 & 0.379 \\
\hline Hunt Lvl (high) & 2 & 0.703 & -139.3 & 85.77 \\
\hline Wolves & 3 & 0.505 & 0.815 & 0.472 \\
\hline Study Area $_{(\text {Garnet })}$ :Time & 4 & 0.384 & 0.036 & 0.034 \\
\hline Study $\operatorname{Area}_{(\mathrm{NGYE})}$ :Time & 4 & 0.384 & -0.034 & 0.033 \\
\hline $\operatorname{Sex}_{(\text {male })}:$ Hunt Lvl $($ high $)$ & 5 & 0.217 & -0.375 & 0.105 \\
\hline
\end{tabular}

${ }^{\text {a }}$ HC Mort = Annual proportion of population killed from human-causes.

b Wolves $=$ Catagorical variable indicating presence of a resident wolf population .

c Dispersal distance measured as number of average home range diameters crossed $\left(D_{h r d}\right)$.

${ }^{\mathrm{d}}$ Hunt $\mathrm{Lvl}=$ Level of puma harvest in an area categorized as (high $>1.4$ pumas/ $1000 \mathrm{~km}^{2} /$ year).

\section{References}

Balme, G.A., Slotow, R., Hunter, L.T.B., 2010. Edge effects and the impact of nonprotected areas in carnivore conservation: leopards in the Phinda-Mkhuze Complex, South Africa. Anim. Conserv. 13, 315-323.

Beier, P., 1995. Dispersal of juvenile cougars in fragmented habitat. J. Wildlife Manage. 59, 228-237.

Beier, P., 2010. A focal species for conservation planning. In: Hornocker, S.N.M. (Ed.) Cougar Ecology and Conservation. The University of Chicago Press, Chicago, USA, pp. 177-189.

Botsford, L.W., Brumbaugh, D.R., Grimes, C., Kellner, J.B., Largier, J., O’Farrell, M.R., Ralston, S., Soulanille, E., Wespestad, V., 2009. Connectivity, sustainability, and yield: bridging the gap between conventional fisheries management and marine protected areas. Rev. Fish Biol. Fisheries 19, 1573-5184.

Bowler, D.E., Benton, T.G., 2005. Causes and consequences of animal dispersal strategies: relating individual behaviour to spatial dynamics. Biol. Rev. 80, 205225

Braunisch, V., Home, R., Pellet, J., Arlettaz, R., 2012. Conservation science relevant to action: a research agenda identified and prioritized by practitioners. Biol. Conserv. 153, 201-210.

Burnham, K.P., Anderson, D.R., 1998. Model Selection and Inference: A Practical Information-Theoretic Approach. Springer-Verlag, New York.

Cooley, H., Wielgus, R., Koehler, G., Robinson, H., Maletzke, B., 2009a. Does hunting regulate cougar populations? A test of the compensatory mortality hypothesis. Ecology 90, 2913-2921.

Cooley, H.S., Wielgus, R.B., Koehler, G., Maletzke, B., 2009b. Source populations in carnivore management: cougar demography and emigration in a lightly hunted population. Anim. Conserv. 12, 321-328.

Cooper, C.B., Daniels, S.J., Walters, J.R., 2008. Can we improve estimates of juvenile dispersal distance and survival? Ecology 89, 3349-3361.

Cougar Management Guidelines Working Group, 2005. Cougar Management Guidelines. WildFutures, Bainbridge Island, Washington.

DeSimone, R., Semmens, B., 2005. Garnet Mountans Mountain Lion Research Progress Report. Montana Fish, Wildlife and Parks, Helena, MT.

Figueira, W.F., Crowder, L.B., 2006. Defining patch contribution in source-sink metapopulations: the importance of including dispersal and its relevance to marine systems. Popul. Ecol. 48, 215-224.

Franklin, A.B., Gutierrez, R.J., Nichols, J.D., 2004. Population dynamics of the California spotted owl (Strix occidentalis occidentalis): a meta-analysis. Ornithol. Monogr. 54, 1-55.
Gaillard, J.M., Festa-Bianchet, M., Yoccoz, N.G., Loison, A., Toigo, C., 2000. Temporal variation in fitness components and population dynamics of large herbivores. Annu. Rev. Ecol. Syst. 31, 367-393.

Griffin, P.C., Mills, L.S., 2009. Sinks without borders: snowshoe hare dynamics in a complex landscape. Oikos.

Gundersen, G., Andreassen, H.P., Ims, R.A., 2002. Individual and population level determinants of immigration success on local habitat patches: an experimental approach. Ecol. Lett. 5, 294-301.

Gundersen, G., Johannesen, E., Andreassen, H.P., Ims, R.A., 2001. Source-sink dynamics: how sinks affect demography of sources. Ecol. Lett. 4, 14-21.

Harris, N.C., 2007. Monitoring survival of young in ungulates: a case study with Rocky Mountain elk. Wildlife Biology. University of Montana, Missoula, MT, 71.

Hixon, M.A., Pacala, S.W., Sandin, S.A., 2002. Population regulation: historical context and contemporary challenges of open vs. closed systems. Ecology 83 1490-1508.

Howard, W.E., 1960. Innate and environmental dispersal of individual vertebrates. Am. Midl. Nat. 63, 152-161.

Johnson, H.E., Mills, L.S., Stephenson, T.R., Wehausen, J.D., 2010. Population-specific vital rate contributions influence management of an endangered ungulate. Ecol. Appl. 20, 1753-1765.

Joshi, N.V., Gadgil, M., 1991. On the role of refugia in promoting prudent use of biological resources. Theor. Popul. Biol. 40, 211-229.

Kluyver, H.N., Tinbergen, 1970. Territory and the regulation of density in titmice. In: Klopfer, P.H. (Ed.), Behavioral Ecology. Dickenson Publishing, Belmont, pp. 112135.

Koenig, W.D., Van Vuren, D., Hooge, P.N., 1996. Detectability, philopatry, and the distribution of dispersal distances in vertebrates. Trends Ecol. Evol. 11, 514517.

Labonte, J., Ouellet, J., Courtois, R., Belisle, F., 1998. Moose dispersal and its role in the maintenance of harvested populations. J. Wildlife Manage. 62, 225-235.

Laing, S.P., Lindzey, F.G., 1993. Patterns of replacement of resident cougars in Southern Utah. J. Mammal. 74, 1056-1058.

Logan, K.A., Sweanor, L.L., 2001. Desert Puma: Evolutionary Ecology and Conservation of an Enduring Carnivore. Island Press, Washington, DC.

Matthysen, E., 2005. Density-dependent dispersal in birds and mammals. Ecography 28, 403-416.

McCullough, D.R., 1996. Spatially structured populations and harvest theory. J. Wildlife Manage. 60, 1-9.

Morrison, J.L., Wood, P.B., 2009. Broadening our approaches to studying dispersal in raptors. J. Raptor Res. 43, 81-89.

Murphy, K.M., 1998. The Ecology of the Cougar (Puma concolor) in the Northern Yellowstone Ecosystem: Interactions with Prey, Bears, and Humans. University of Idaho, Moscow, Idaho, p. 147.

Murphy, K.M., Ross, P.I., Hornocker, M.G., 1999. The ecology of anthropogenic influences on cougars. In: Clark, A.P.C.T.W., Minta, S.C., Kareiva, P.M. (Eds.), Carnivores in Ecosystems. Yale University Press, New Haven, Connecticut, pp 77-101.

Newby, J.R., 2011. Puma dispersal ecology in the Central Rocky Mountains. Wildlife Biology. University of Montana, Missoula, Montana, i-104.

Novaro, A.J., Funes, M.C., Walker, R.S., 2005. An empirical test of source-sink dynamics induced by hunting. J. Appl. Ecol. 42, 910-920.

Oli, M.K., Dobson, F.S., 2003. The relative importance of life-history variables to population growth rate in mammals: Cole's prediction revisited. Am. Nat. 161 423-440.

Rabinowitz, A., Zeller, K.A., 2010. A range-wide model of landscape connectivity and conservation for the jaguar, Panthera onca. Biol. Conserv. 143, 939-945.

Revilla, E., Palomares, F., Wiegand, T., Ferreras, P., Delibes, M., 2004. Effects of matrix heterogeneity on animal dispersal: from individual behavior to metapopulation-level parameters. Am. Nat., 164.

Robinson, H., DeSimone, R., 2011. The Garnet Range Mountain Lion Study: Characteristics of a Hunted Population in West-Central Montana. Montana Department of Fish, Wildlife \& Parks, Helena, MT, p. 102.

Robinson, H.S., Wielgus, R.B., Cooley, H.S., Cooley, S.W., 2008. Sink populations in carnivore management: cougar demography and immigration in a hunted population. Ecol. Appl. 18, 1028-1037.

Ross, P.I., Jalkotzy, M.G., 1992. Characteristics of a hunted population of cougars in Southwestern Alberta. J. Wildlife Manage. 56, 417-426.

Runge, J.P., Runge, M.C., Nichols, J.D., 2006. The role of local populations within a landscape context: defining and classifying sources and sinks. Am. Nat. 167, 925-938

Ruth, T.K., 2004. Patterns of Resource Use among Cougars and Wolves in Northwestern Montana and British Columbia. University of Idaho, Department of Natural Resources, Moscow, ID.

Ruth, T.K., Buotte, P., Haroldson, M., Murphy, K., Hornocker, M., Quigley, H., 2008 Cougar reproduction and survival pre- and post-wolf reintroduction in Yellowstone National Park. In: Nadeau, S. (Ed.), Proceedings of the Ninth Mountain Lion Workshop. Idaho Department of Fish and Game, Sun Valley, Idaho, p. 61.

Ruth, T.K., Buotte, P.C., 2007. Cougar ecology and cougar-carnivore interactions in Yellowstone National Park. Final Technical Report. Hornocker Wildlife Institute/ Wildlife Conservation Society, Bozeman, Montana.

Ruth, T.K., Buotte, P.C., Quigley, H.B., 2010. Comparing ground telemetry and global positioning system methods to determine cougar kill rates. J. Wildlife Manage. 74, 1123-1133. 
J.R. Newby et al./Biological Conservation 159 (2013) 230-239

239

Ruth, T.K., Haroldson, M.A., Murphy, K.M., Butte, P.C., Hornocker, M.G., Quigley, H.B., 2011. Cougar survival and source-sink structure on the greater Yellowstone northern range. J. Wildlife Manage. 75, 1381-1398.

Ruth, T.K., Murphy, K., 2010. Competition with other carnivores for prey. In: Hornocker, M., Negri, S. (Eds.), Cougar Ecology and Conservation. University of Chicago Press, Chicago, pp. 163-172.

Saether, B.E., Bake, O., 2000. Avian life history variation and contribution of demographic traits to the population growth rate. Ecology 81, 642-653.

Schwartz, C.C., Haroldson, M.A., White, G.C., 2010. Hazards affecting grizzly bear survival in the Greater Yellowstone Ecosystem. J. Wildlife Manage. 74, 654667.

Small, R.J., Holzwart, J.C., Kusch, D.H., 1991. Predation and hunting mortality of ruffed grouse in central Wisconsin. J. Wildlife Manage. 55, 512-520.

Smith, D.W., Bangs, E.E., Oakleaf, J.M., Mack, C., Foantaine, J., Boyd, D.K., Jimenez, M., Pletscher, D.H., Niemeyer, C.C., Meier, T.J., Stabler, D.R., Hoyan, J., Asher, V.J., Murray, D.L., 2010. Survival of colonizing wolves in the northern Rocky Mountains of the United States, 1982-2004. J. Wildlife Manage. 74, 620-634.

Smith, J.L.D., 1993. The role of dispersal in structuring the Chitwan tiger population. Behaviour 124, 165-195.

Stoner, D.C., Wolfe, M.L., Choate, D.M., 2006. Cougar exploitation levels in Utah: implications for demographic structure, population recovery, and metapopulation dynamics. J. Wildlife Manage. 70, 1588.
Sutherland, W.J., Gill, J.A., Norris, K., 2002. Density-dependent dispersal in animals: concepts, evidence, mechanisms and consequences. In: Bullock, R.E.K.J.M., Hails, R.S. (Eds.), Dispersal Ecology. Blackwell Science, Ltd., Oxford, UK, pp. 134-153.

Sweanor, L.L., Logan, K.A., Hornocker, M.G., 2000. Cougar dispersal patterns, metapopulation dynamics, and conservation. Conserve. Biol. 14, 798-808.

Thomas, C.D., Kunin, W.E., 1999. The spatial structure of populations. J. Anim. Ecol. $68,647-657$.

Thompson, D.J., Jenks, J.A., 2005. Long-distance dispersal by a subadult male cougar from the Black Hills, South Dakota. J. Wildlife Manage. 69, 818-820.

Trewhella, W.J., Harris, S., McAllister, F.E., 1988. Dispersal distance, home-range size and population density in the red fox (Vulpes vulpes): a quantitative analysis. J. Apple. Ecol. 25, 423-434.

Weser, P.M., 1985. Does competition drive dispersal? Ecology 66, 1170-1175.

Wielgus, R.B., Sarrazin, F., Ferriere, R., Clobert, J., 2001. Estimating effects of adult male mortality on grizzly bear population growth and persistence using matrix models. Biol. Conserve. 98, 293-303.

Williamson, 2004. Overview and synthesis: the tale of the tail. In: Bullock, R.E.K.J.M., Hails, R.S. (Eds.), Dispersal Ecology. Blackwell Science Limited, Oxford, pp. 431-444.

Wolff, J.O., 1997. Population regulation in mammals: an evoloutionary perspective. J. Anim. Ecol. 66, 1-13.

Woodroffe, R., Ginsberg, J.R., 1998. Edge effects and the extinction of populations inside protected areas. Science 280, 2126-2128. 